(2) Open Access Full Text Article

\title{
Efficacy and safety of different doses of a slow release corticosteroid implant for macular edema
}

This article was published in the following Dove Press journal:

Drug Design, Development and Therapy

20 April 2016

Number of times this article has been viewed

John Hall

Medical Affairs, Alimera Sciences Ltd., Aldershot, Hampshire, UK
Correspondence: John Hall

Alimera Sciences Ltd., Royal Pavilion,

Wellesley Road, Aldershot, Hampshire

GUII IPZ, UK

Tel +44 I252 354036

Fax +44 I252354 012

Email john.hall@alimerasciences.com

\section{Dear editor}

I read "Efficacy and safety of different doses of a slow release corticosteroid implant for macular edema: meta-analysis of randomized controlled trials" published in May 2015 by Liu et al. ${ }^{1}$ The purpose of this article was to report the meta-analysis for the efficacy and safety of intravitreal corticosteroid implants for macular edema. However, there are some factual errors which mean the current article is misleading and these errors need to be pointed out to the readers of Drug Design, Development and Therapy.

First point - from the title of the article, the reader is expecting to read about corticosteroids that are licensed for use for macular edema. At this point the author should have specified that the therapy area being reviewed is diabetic macular edema (DME) and that Retisert (fluocinolone acetonide) is not licensed for this indication. ${ }^{2}$ ILUVIEN $^{\circledR}$ (190 micrograms fluocinolone acetonide intravitreal implant in applicator) and Ozurdex (dexamethasone), ${ }^{3}$ however, are indicated for the treatment of DME.

Second point - ILUVIEN now has marketing authorizations in Austria, Belgium, the Czech Republic, Denmark, Finland, France, Germany, Ireland, Italy, Luxembourg, the Netherlands, Norway, Poland, Portugal, Spain, Sweden, and the United Kingdom for the treatment of vision impairment associated with chronic DME, considered insufficiently responsive to available therapies. ${ }^{4}$ Contrary to the statement in the "Discussion", in November 2014 ILUVIEN was approved by the US Food and Drug Administration for the treatment of DME in patients who have previously been treated with a course of corticosteroids and did not have a clinically significant rise in intraocular pressure. ${ }^{5}$ Hence there are slight differences between the European and USA licenses (these are summarized in Table 1).

Third point - in Europe the license for ILUVIEN is based on efficacy data reported at 36 months in the FAME trials. ${ }^{6}$ In Table 1 the authors cite Retisert, which is not the name of the licensed medicine, and support this with data from Campochiaro et al published in 2011. However, this is misleading as the study cited was performed with ILUVIEN and has now been superseded by Campochiaro et al in 2012 which reports the 3 -year results. ${ }^{6}$

Fourth point - the authors refer to the efficacy and safety data for ILUVIEN and Ozurdex but have not accurately presented the current data and corrected the data to reflect USA and European licensed data. Table 1 has been generated to help the reader understand the differences between pivotal trial data for ILUVIEN and Ozurdex ${ }^{6,7}$ and the licensed indications for ILUVIEN in the USA and Europe. ${ }^{6,7}$

In conclusion, it is hoped that the inaccuracies that have been identified will help clarify that ILUVIEN ${ }^{\circledR}$ is an approved therapy for the treatment of DME and available 

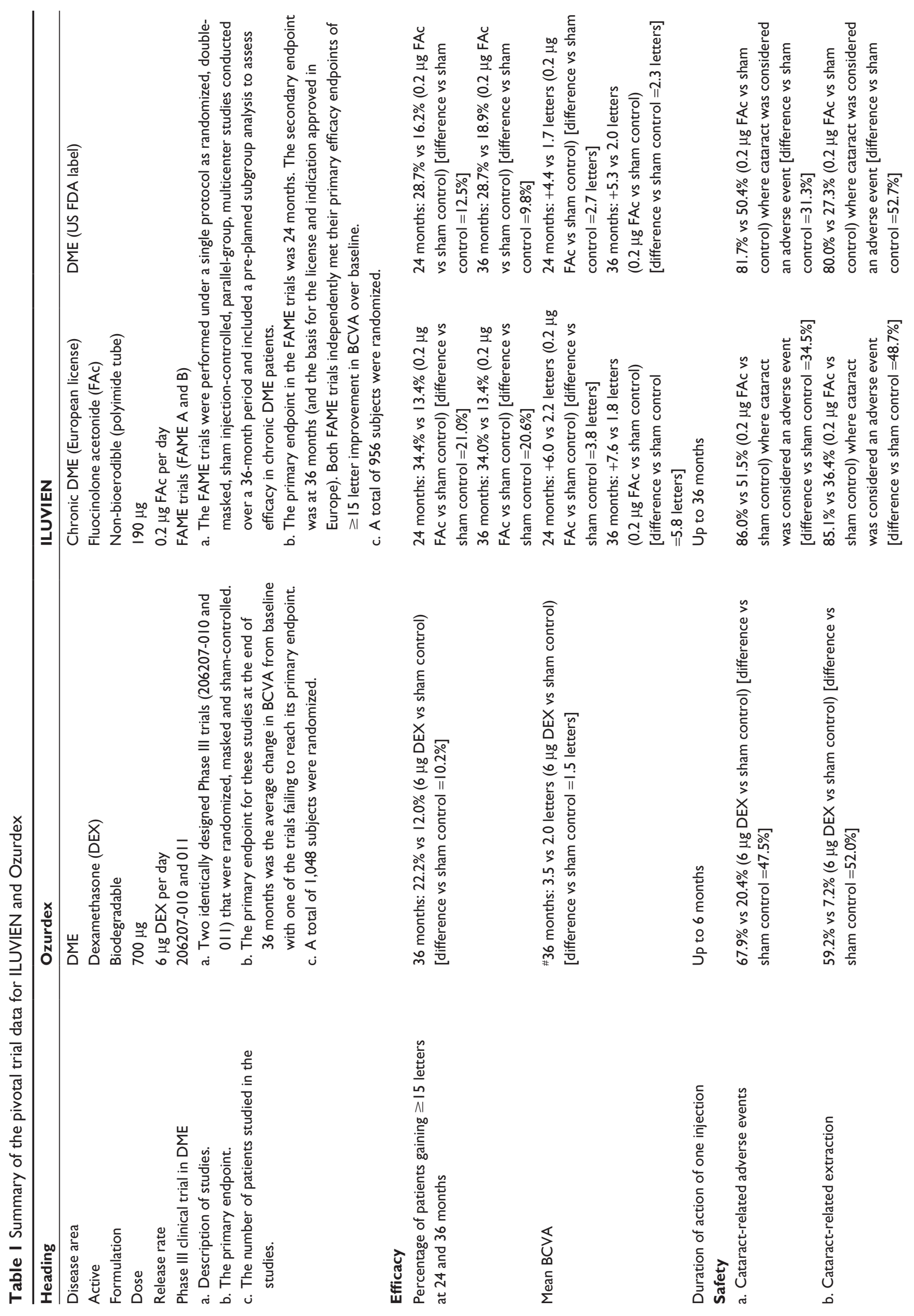


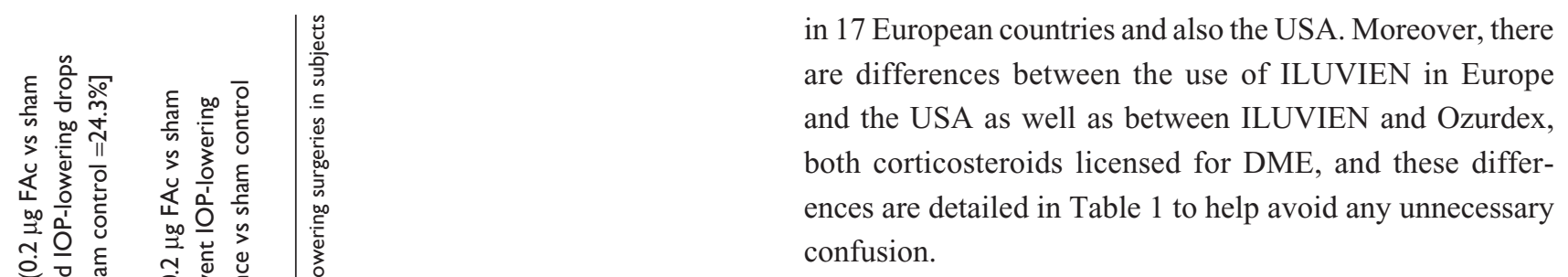

\section{Disclosure}

The author is a consultant in medical affairs to Alimera Sciences in Europe.

\section{References}

1. Lui Q, He M, Shi H, et al. Efficacy and safety of different doses of a slowrelease corticosteroid implant for macular edema: meta-analysis of randomized controlled trials. Drug Des Devel Ther. 2015;9:2527-2535.

2. Hall J. Comment on: "Use of the Fluocinolone Acetonide Intravitreal Implant for the Treatment of Noninfectious Posterior Uveitis: 3-Year Results of a Randomized Clinical Trial in a Predominantly Asian Population". Ophthalmol Ther. 2015;4(1):65-66.

3. Hall J. Letter to the editor: dexamethasone intravitreal implant in the treatment of diabetic macular edema. Clin Ophthalmol. 2015;9: 2119-2121.

4. medicinces.org.uk [homepage on the Internet]. Summary of Product Characteristics for ILUVIEN $190 \mu \mathrm{g}$ intravitreal implant in applicator. EMC; 2015 [updated November 9, 2015]. Available from: https://www. medicines.org.uk/emc/medicine/27636. Accessed: March 19, 2016.

5. Alimera Sciences. [press release]. Available from: http://investor. alimerasciences.com/releasedetail.cfm?ReleaseID $=873291$. Accessed 26 February 2016.

6. Campochiaro PA, Brown DM, Pearson A, et al. Sustained delivery fluocinolone acetonide vitreous inserts provide benefit for at least 3 years in patients with diabetic macular edema. Ophthalmology. 2012;119(10): 2125-2132.

7. Boyer DS, Yoon YH, Belfort R Jr, et al. Three-year, randomized, shamcontrolled trial of dexamethasone intravitreal implant in patients with diabetic macular edema. Ophthalmology. 2014;121(10):1904-1914. 


\section{Authors' reply \\ Qingyu Liu ${ }^{\prime, 2}$ \\ Jing Yu'}

'Department of Ophthalmology, Shanghai Tenth People's Hospital, Shanghai, People's Republic of China; ${ }^{2}$ Tongji University School of Medicine, Shanghai, People's Republic of China

Correspondence: Jing Yu

Department of Ophthalmology, Shanghai Tenth People's Hospital,

301 Yanchang Road, Shanghai 200072, People's Republic of China

Email dryujing@aliyun.com

\section{Dear editor}

Thank you for your letter. We really appreciate your rigor and conscientiousness. We will give a response one by one.

First point - in our selection criteria, we list the criteria, "inclusion of a comparison of different doses of any intravitreal corticosteroid implant for the treatment of any type of ME [macular edema]'. In Campochiaro et al's research, the fluocinolone acetonide vitreous inserts were used for diabetic macular edema. ${ }^{1}$

Second point - Dr Hall states that ILUVIEN ${ }^{\circledR}$ was approved by the US Food and Drug Administration in November 2014, which was contrary to our "Discussion". However, in our literature search, we mentioned that, "A systematic English language search was conducted from inception to November 2014". 2 "ILUVIEN ${ }^{\circledR}$ is approved for use in several European countries (Austria, France, Germany, Portugal, and Spain and is pending approval in Italy) for the treatment of impairment of vision associated with chronic diabetic macular edema that is insufficiently responsive to available therapies. It has yet to receive approval by the FDA for use in the United States". 3

Third point - we have mistaken the fluocinolone acetonide (FA) intravitreal inserts for Retisert, both of which were loaded with FA. We regret that and we will submit a corrigendum. We thank Dr Hall for pointing that out. Both of the studies by the FAME Study Group were included in our first 14 reports. The identifiers of the two researches registered at www.clinicaltrials.gov are the same: NCT 0034968, which means most of these data and patients were the same. To avoid bias and repeat of data analysis, we chose the report published in 2011, ${ }^{1}$ which had the lower percentage of patients who failed to remain in the study at the endpoint and a larger sample.

Fourth point - the purpose of our meta-analysis was to assess the efficacy and safety of intravitreal corticosteroid implants for macular edema. Data were extracted from each included report published before November 2014. Different study groups conducting these included randomized controlled trials in dozens of countries. We analyzed these data synthetically instead of subdividing by different area. We really appreciate Dr Hall's carefulness. The table is perspicuous, clarifying the indication and management of these sustained-release corticosteroid options.

\section{Disclosure}

The authors have no conflict of interest in this communication.

\section{References}

1. Campochiaro PA, Brown DM, Pearson A, et al. Long-term benefit of sustained-delivery fluocinolone acetonide vitreous inserts for diabetic macular edema. Ophthalmology. 2011;118(4):626-635.e2.

2. Lui Q, He M, Shi H, et al. Efficacy and safety of different doses of a slowrelease corticosteroid implant for macular edema: meta-analysis of randomized controlled trials. Drug Des Devel Ther. 2015;9:2527-2535.

3. Cabrera M, Yeh S, Albini TA. Sustained-release corticosteroid options. J Ophthalmol. 2014;2014:164692.

Dove Medical Press encourages responsible, free and frank academic debate. The content of the Drug Design, Development and Therapy 'letters to the editor' section does not necessarily represent the views of Dove Medical Press, its officers, agents, employees, related entities or the Drug Design, Development and Therapy editors. While all reasonable steps have been taken to confirm the content of each letter, Dove Medical Press accepts no liability in respect of the content of any letter, nor is it responsible for the content and accuracy of any letter to the editor.

\section{Publish your work in this journal}

Drug Design, Development and Therapy is an international, peerreviewed open-access journal that spans the spectrum of drug design and development through to clinical applications. Clinical outcomes, patient safety, and programs for the development and effective, safe, and sustained use of medicines are a feature of the journal, which has also been accepted for indexing on PubMed Central. The manuscript management system is completely online and includes a very quick and fair peer-review system, which is all easy to use. Visit http://www.dovepress.com/testimonials.php to read real quotes from published authors. 